\title{
Prenatal detection of chromosomal abnormalities and copy number variants in fetuses with congenital gastrointestinal obstruction
}

Xinyue Meng ${ }^{1}$ and Lili Jiang ${ }^{2^{*}}$

\begin{abstract}
Background: Congenital gastrointestinal obstruction (CGIO) mainly refers to the stenosis or atresia of any part from the esophagus to the anus and is one of the most common surgical causes in the neonatal period. The concept of genetic factors as an etiology of CGIO has been accepted, but investigations about CGIO have mainly focused on aneuploidy, and the focus has been on duodenal obstruction. The objective of this study was to evaluate the risk of chromosome aberrations (including numeric and structural aberrations) in different types of CGIO. A second objective was to assess the risk of abnormal CNVs detected by copy number variation sequencing (CNV-seq) in fetuses with different types of CGIO.

Methods: Data from pregnancies referred for invasive testing and CNV-seq due to sonographic diagnosis of fetal CGIO from 2015 to 2020 were obtained retrospectively from the computerized database. The rates of chromosome aberrations and abnormal CNV-seq findings for isolated CGIOs and complicated CGIOs and different types of CGIOs were calculated.

Results: Of the 240 fetuses with CGIO that underwent karyotyping, the detection rate of karyotype abnormalities in complicated CGIO was significantly higher than that of the isolated group (33.8\% vs. $10.8 \%, p<0.01$ ). Ninety-three cases with normal karyotypes further underwent CNV-seq, and CNV-seq revealed an incremental diagnostic value of 9.7\% over conventional karyotyping. In addition, the incremental diagnostic yield of CNV-seq analysis in complicated CGIOs (20\%) was higher than that in isolated CGIOs (4.8\%), and the highest prevalence of pathogenic CNVs/likely pathogenic CNVs was found in the duodenal stenosis/atresia group (17.5\%), followed by the anorectal malformation group (15.4\%). The 13q deletion, 10q26 deletion, 4q24 deletion, and 2p24 might be additional genetic etiologies of duodenal stenosis/atresia.
\end{abstract}

Conclusions: The risk of pathogenic chromosomal abnormalities and CNVs increased in the complicated CGIO group compared to that in the isolated CGIO group, especially when fetuses presented duodenal obstruction (DO) and anorectal malformation. CNV-seq was recommended to detect submicroscopic chromosomal aberrations for DO and

\footnotetext{
*Correspondence: jianglili87@163.com

2 Department of Obstetrics and Gynecology, Shengjing Hospital

of China Medical University, NO. 36, Sanhao Street, Liaoning Province

110004 Shenyang, China

Full list of author information is available at the end of the article
}

(C) The Author(s) 2022. Open Access This article is licensed under a Creative Commons Attribution 4.0 International License, which permits use, sharing, adaptation, distribution and reproduction in any medium or format, as long as you give appropriate credit to the original author(s) and the source, provide a link to the Creative Commons licence, and indicate if changes were made. The images or other third party material in this article are included in the article's Creative Commons licence, unless indicated otherwise in a credit line to the material. If material is not included in the article's Creative Commons licence and your intended use is not permitted by statutory regulation or exceeds the permitted use, you will need to obtain permission directly from the copyright holder. To view a copy of this licence, visit http://creativecommons.org/licenses/by/4.0/. The Creative Commons Public Domain Dedication waiver (http://creativecommons.org/publicdomain/zero/1.0/) applies to the data made available in this article, unless otherwise stated in a credit line to the data. 
anorectal malformation when the karyotype was normal. The relationship between genotypes and phenotypes needs to be explored in the future to facilitate prenatal diagnosis of fetal CGIO and yield new clues into their etiologies.

Keywords: Congenital gastrointestinal obstruction, Copy number variation sequencing, Karyotype, Copy number variation

\section{Background}

Congenital gastrointestinal obstruction (CGIO) mainly refers to the stenosis or atresia of any part from the esophagus to the anus and is one of the most common surgical causes in the neonatal period, with an incidence of 1 in every 2000 newborns [1]. Esophageal stenosis/ atresia represents a life-threatening condition in the upper gastrointestinal tract, and duodenal stenosis/atresia and jejunoileal stenosis/atresia represent the major causes of CGIO, with an incidence ranging from 1.3 to 2.8 out of 10000 live births in the lower gastrointestinal tract $[2,3]$. Colonic stenosis/atresia, the less frequent form of lower gastrointestinal tract atresia, and anorectal malformation are also included in lower gastrointestinal tract atresia. CGIO is associated with complex embryological and genetic factors. The 4-8th week of gestation in the embryonic period is known as the developmental origin of CGIO. For esophageal stenosis/atresia, a failure of invagination of the lateral trachea-esophageal grooves is proposed. Duodenal stenosis/atresia is believed to result from failure of bowel recanalization following a temporary solid stage, while the probable cause of jejunoileal stenosis/atresia and colonic stenosis/atresia may be a late mesenteric vascular accident. An impaired process in the urorectal septum might lead to anorectal malformation [4-6].

In addition to embryological factors, the concept of genetic factors as an etiology of CGIO has been generally accepted $[7,8]$. The Prevention Network in the United States shows that gastrointestinal malformations are often correlated with trisomy 13, 18, 21 and Turner syndrome, in which the associations between duodenal stenosis/atresia and trisomy 21, esophageal stenosis/ atresia and trisomy 18 are especially prominent [9]. With the wide application of high-resolution chromosome analysis technology in prenatal diagnosis, increasing evidence has shown that pathogenic copy number variants (pCNVs) account for a certain proportion of fetuses with ultrasound abnormalities. In recent years, chromosomal microarray analysis (CMA) has become a mature clinical high-resolution chromosome analysis technique for detecting submicroscopic chromosomal imbalances. However, the high cost and low throughput of CMA restrict its application as a routine detection method for prenatal diagnosis. With the development of next-generation sequencing (NGS) technology, NGS-based copy number variation sequencing (CNV-seq) technology has gradually developed into a high-throughput, high-resolution, short turn-around time, and low-cost detection method [10], and it has been utilized in most prenatal diagnoses as a viable alternative methodology to CMA $[11,12]$. A few studies have shown that DO is also related to $\mathrm{CNVs}$, such as $4 \mathrm{q} 22.3$ deletion [13] and 13q deletion $[14,15]$. Nevertheless, genetic investigations of CGIO have mainly focused on aneuploidy, and the focus has been on DO.

Therefore, the objective of this study was to evaluate the risk of chromosome aberrations (including numeric and structural aberrations) by karyotyping in different types of CGIO. A second objective was to assess the risk of abnormal CNVs detected by CNV-seq in fetuses with different types of CGIO to provide better prenatal counseling and clinical management.

\section{Methods \\ Subjects}

We retrospectively analyzed fetuses with CGIO, alone or in combination with some soft markers and structural abnormalities, who had undergone invasive prenatal diagnosis from January 2015 to January 2020 in a tertiary care university hospital in China. Cases with failed amniocentesis or culture failure or with an abnormal family history were excluded. Our study was approved by the local Ethics Committee (approval no. 2015PS235K), and all pregnant women provided verbal consent to participate in this study via telephone.

\section{Ultrasonographic examination}

Ultrasonographic examination was performed by two specialized sonographers using Voluson E8 or Voluson E10, Pro, Exp (GE, Milan, Italy) equipped with a 4-8 MHz transabdominal transducer. When fetal CGIO was detected, detailed anatomic scanning and fetal echocardiography were performed for each fetus. According to whether fetal CGIO was found in combination with any soft marker or other structural abnormalities, they were divided into isolated CGIO and complicated CGIO. Polyhydramnios was not included as an abnormality in this study because its development was mostly secondary to gastrointestinal obstruction. 


\section{Cytogenetic analysis}

Chromosome analysis of the fetuses was obtained using amniocentesis or cordocentesis according to the gestational weeks, which was calculated according to the last menstrual period, crown-rump length or ultrasonographic estimation. Karyotype analysis was performed according to the G-banded karyotyping protocol on all fetal samples.

Genomic DNA (gDNA) was extracted from amniotic fluid or cord blood using the Genomic DNA Extraction Kit (Qiagen, Hilden, Germany), and then the gDNA was purified using the Purification DNA kit (Zymo Research). Invitrogen Qubit 2.0 (Thermo Fisher Scientific) was used to quantitate the concentration of gDNA. Next, the DNA library was constructed using a non-invasive prenatal test library prep kit (Berry Genomics), in which each sample was indexed by 6 bp indexing oligos. Then, the DNA library was purified using the Purification DNA libraries for NGS kit from Berry Genomics. DNA libraries were quantitated using the Kapa SYBR fast qPCR kit (Kapa Biosystems), and the DNA standard was greater than $25 \mathrm{nmol} / \mathrm{L}$. Then, the quantitated DNA libraries were subjected to massively parallel sequencing on the NextSeq 500 platform (Illumina), generating approximately 5 million raw sequencing reads with 36 bp genomic DNA sequences. More than 2.5 million reads were uniquely analyzed through the software provided by Berry Genomics. Several public databases, including DGV (http://projects. tcag.ca/variation), DECIPHER (http://decipher.sanger. ac.uk/), Online Mendelian Inheritance in Man (http:// www.omim.org), ClinGen (https://www.clinicalgenome. org/), UCSC (http://genome.ucsc.edu/, hg19), and PubMed (http://www.ncbi.nlm.nih.gov/pubmed), were utilized to interpret the results as gains and losses of copy number. CNVs were classified as pathogenic, benign or variants of unknown significance (VOUS). According to the American College of Medical Genetics standards and guidelines for the interpretation and reporting of postnatal constitutional CNVs, the VOUS category was further subdivided into likely pathogenic, VOUS and likely benign variants [16]. In our study, only pathogenic CNVs (pCNVs), likely pCNVs and VOUS were recorded.

\section{Follow up}

Operative reports and medical records were followed up to confirm the diagnosis of congenital gastrointestinal atresia for liveborn cases. A telephone follow-up was performed for patients who did not undergo surgery in our hospital. The development of the surviving infants was performed by trained pediatricians until 1 year old.

\section{Statistical analysis}

Statistical analysis was performed with SPSS Statistics version 26 software (IBM, Armonk, NY, USA). Continuous variables were documented as the mean and the standard deviation (SD), and categorical variables were documented as percentages. The chi-square test or Fisher's exact test was applied to compare the significance of differences among CGIO groups. A p value $<0.05$ was considered significant.

\section{Results \\ Subjects}

A total of 240 fetuses prenatally diagnosed with CGIO were enrolled in this study from 2015 to 2020 . The maternal age was $29.45 \pm 4.61$ years (range, 21-43), and the gestational age at invasive testing was $27.39 \pm 3.83$ weeks (range, 19-35).

\section{Ultrasonography findings}

Of the 240 cases, there were 28 cases of esophageal stenosis/atresia, 134 cases of duodenal stenosis/atresia, 43 cases of jejunoileal stenosis/atresia, 10 cases of colonic stenosis/atresia and 25 anorectal malformations. All cases were classified into 2 groups: either isolated CGIO $(69.2 \%, 166 / 240)$ or CGIO with other abnormalitiescomplicated CGIO $(30.8 \%, 74 / 240)$. The demographic characteristics concerning isolated CGIOs and complicated CGIOs are presented in Table 1 . The main accompanying abnormalities included nasal bone absence (8), single umbilical artery (12), persistent right umbilical vein (4), ventriculomegaly (5), fetal growth restriction (4), hydronephrosis (2), persistent left superior vena cava (7), tetralogy of fallot (1), pulmonic stenosis (1), ventricular septal defect (2), complete atrioventricular canal malformation (1), complete transposition of great arteries (1), renal agenesis (1), complex congenital heart disease (2), multiple echo enhancement foci in the abdominal cavity (1), gallbladder not shown (1), strephenopodia (1), shortened bones (4), echogenic bowel (1), diaphragmatocele (1), microtia (1), ventricular ependymal cysts (1), dysplasia of the septum pellucidum (2), renal cyst (1), ascites (3), situs inversus viscerum (1), cervical lymphatic hygroma (3), enlarged cisterna magna (1), vermian hypoplasia (1), situs inversus (2), polyhydramnios (92), and multiple malformations (9).

\section{Karyotyping}

Table 2 shows the distribution and incidence rates of karyotype abnormalities in the isolated CGIO group and complicated CGIO group. The karyotype analysis of 240 fetuses with CGIO identified 43 cases with pathogenic variants, with an overall detection rate of $17.9 \%$ 
Table 1 Demographic characteristics of pregnancies with CGIO

\begin{tabular}{|c|c|c|c|}
\hline Characteristic & Total $(n=240)$ & Isolated CGIO $(n=166)$ & $\begin{array}{l}\text { Complicated } \\
\text { CGIO }(n=74)\end{array}$ \\
\hline Maternal age (years), mean \pm SD & $29.45 \pm 4.61$ & $29.41 \pm 4.62$ & $29.57 \pm 4.61$ \\
\hline $\begin{array}{l}\text { Gestational age at invasive testing (weeks), } \\
\text { mean } \pm S D\end{array}$ & $27.39 \pm 3.83$ & $27.42 \pm 3.95$ & $27.34 \pm 3.54$ \\
\hline $\mathrm{BMI}$, mean $\pm \mathrm{SD}$ & $26.3 \pm 4.1$ & $26.1 \pm 3.9$ & $26.4 \pm 3.8$ \\
\hline \multicolumn{4}{|l|}{ Parity } \\
\hline Primipara, n (\%) & $157(65.4)$ & $106(63.9)$ & $51(68.9)$ \\
\hline Multipara, n (\%) & $83(34.6)$ & $60(36.1)$ & $23(31.1)$ \\
\hline \multicolumn{4}{|l|}{ Gestational count } \\
\hline Singleton, $\mathrm{n}(\%)$ & $225(93.8)$ & $162(97.6)$ & $63(85.1)$ \\
\hline twins, n (\%) & $15(6.2)$ & $4(2.4)$ & $11(14.9)$ \\
\hline \multicolumn{4}{|l|}{ Fetal gender } \\
\hline Male, n (\%) & $122(50.8)$ & $96(57.8)$ & $26(35.1)$ \\
\hline Female, n (\%) & $118(49.2)$ & $70(42.2)$ & $48(64.9)$ \\
\hline
\end{tabular}

CGIO congenital gastrointestinal obstruction, $S D$ standard deviation, $B M I$ body mass index

Table 2 Rates of abnormal karyotypes of fetuses with isolated CGIO and complicated CGIO

\begin{tabular}{|c|c|c|c|}
\hline & Total $(n=240)$ & $\begin{array}{l}\text { Isolated } \\
\text { CGIO } \\
(n=166)\end{array}$ & $\begin{array}{l}\text { Complicated } \\
\text { CGIO }(n=74)\end{array}$ \\
\hline \multicolumn{4}{|l|}{ Numeric } \\
\hline Trisomy 21, n (\%) & $27(11.3)$ & $12(7.2)$ & $15(20.3)$ \\
\hline Trisomy 18, n (\%) & $4(1.7)$ & 0 & $4(5.4)$ \\
\hline $\begin{array}{l}\text { Trisomy 13, n (\%) } \\
47, \text { XXY } \\
\text { Total, n (\%) }\end{array}$ & $\begin{array}{l}2(0.8) \\
1(0.4) \\
34(14.2)\end{array}$ & $\begin{array}{l}0 \\
1(0.6) \\
13(7.8)\end{array}$ & $\begin{array}{l}2(2.7) \\
0 \\
21(28.4)^{\mathrm{a}}\end{array}$ \\
\hline \multicolumn{4}{|l|}{ Structure } \\
\hline Inversion, n (\%) & $1(0.4)$ & $1(0.6)$ & 0 \\
\hline Translocation, n (\%) & $3(1.2)$ & $1(0.6)$ & $2(2.7)$ \\
\hline $\begin{array}{l}\text { Deletion, n (\%) } \\
\text { Total, n (\%) }\end{array}$ & $\begin{array}{l}1(0.4) \\
5(2.1)\end{array}$ & $\begin{array}{l}0 \\
2(1.2)\end{array}$ & $\begin{array}{l}1(1.4) \\
3(4.1)\end{array}$ \\
\hline Others, n (\%) & $4(1.7)$ & $3(1.8)$ & $1(1.4)$ \\
\hline Total, n (\%) & $43(17.9)$ & $18(10.8)$ & $25(33.8)^{a}$ \\
\hline
\end{tabular}

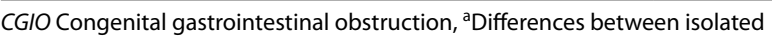
CGIO and complicated CGIO groups were statistically significant $(P<0.01)$

(43/240). Twenty-five cases of karyotype abnormalities were detected in the complicated CGIO group (74 cases), which was a significantly higher rate than that in the isolated group $(25 / 74,33.8 \%$ vs. $18 / 166,10.8 \%, p<0.01)$. Numerous chromosomal abnormalities were significantly more abundant in complicated CGIO than isolated CGIO ( $28.4 \%$ vs. $7.8 \%, p<0.01)$; however, we observed no significant differences in structural chromosomal abnormalities or other abnormalities between complicated CGIO and isolated CGIO (both $p>0.05$ ). Among these cases, numerical chromosome abnormalities were detected in 34 fetuses: trisomy 21 was found in 27 (including 2 mosaic aneuploidies); trisomy 18 , trisomy13, and an aberration of the sex chromosome-47, XXY-were each detected in four, two and one cases, respectively. Structural chromosome aberrations were identified in five fetuses whose karyotypes were 46, XN, inv (9) (p11q13); 45, XN, der (13; 14) (q10; q10); 47, XN, + del (22) (q13); $46, \mathrm{XN}$, der (14), t (6;14) (q21; p11) and 46, XN, t (12;15) (q13; q21). In addition, four cases with mosaicism were also detected, including 45, XN, -13 [1] (SC)/46, XN, del (13) (q14) [1] (SC)/46, XN [42]; 46, XN, del (10) (p11qter) [1] /46, XN [19]; 47, XN, +2 [1] /46, XN [49] and $47, \mathrm{XN},+\operatorname{mar}[33] / 46, \mathrm{XY}$ [9]. The rates of chromosomal abnormalities in fetuses with esophageal stenosis/atresia, duodenal stenosis/atresia, jejunoileal stenosis/atresia, colonic stenosis/atresia and anorectal malformation were $14.3 \%$ (4/28), $25.0 \%$ (33/132), $4.4 \%$ (2/45), 0 and $16.0 \%$ $(4 / 25)$, respectively. The distributions and rates of chromosomal abnormalities for different types of CGIO are shown in Table 3.

\section{CNV-seq results}

Among the 197 cases with normal karyotypes, 93 cases underwent further CNV-seq: chromosomal CNVs were found in 26 cases with a positive rate of $28.0 \%$ (26/93), of which 9 pathogenic/likely pathogenic CNVs were detected in 8 cases $(9.7 \%, 9 / 93), 2$ cases involved VOUS $(2.2 \%, 2 / 93)$, and 16 cases involved benign/likely benign CNVs. The rates of pCNV, likely pCNV and VOUS in different types of CGIO are presented in Table 4, and the related Online Mendelian Inheritance in Man (OMIM) genes are shown in Table 5. CNVs of pathogenic/likely pathogenic $(n=9)$ ranged in size from $0.2 \mathrm{Mb}$ to $9.76 \mathrm{Mb}$, among which were 2 cases with the deletion of $13 \mathrm{q}$ and 2 
Table 3 The distributions and rates of chromosomal abnormalities for different types of CGIO

\begin{tabular}{|c|c|c|c|c|c|c|c|c|c|}
\hline & Total, n (\%) & Trisomy 21 & Trisomy 18 & Trisomy 13 & $47, X X Y$ & Inversion & Translocation & Deletion & Others \\
\hline $\begin{array}{l}\text { esophageal } \\
\text { stenosis/atresia } \\
(n=28)\end{array}$ & $4(14.3)$ & 0 & 3 & 0 & 0 & 0 & Reciprocal (1) & 0 & 0 \\
\hline $\begin{array}{l}\text { duodenal } \\
\text { stenosis/atresia } \\
(n=132)\end{array}$ & $33(25)$ & 27 & 0 & 0 & 1 & $\begin{array}{l}\text { Chromosome } \\
9(1)\end{array}$ & $\begin{array}{l}\text { Robertsonian } \\
\text { (1) } \\
\text { Reciprocal (1) }\end{array}$ & 0 & Mosaicism (2) \\
\hline $\begin{array}{l}\text { jejunoileal } \\
\text { stenosis/atresia } \\
(n=45)\end{array}$ & $2(4.4)$ & 0 & 0 & 0 & 0 & 0 & 0 & 0 & Mosaicism (2) \\
\hline $\begin{array}{l}\text { colonic ste- } \\
\text { nosis/atresia } \\
(n=10)\end{array}$ & $0(0)$ & 0 & 0 & 0 & 0 & 0 & 0 & 0 & 0 \\
\hline $\begin{array}{l}\text { anorectal } \\
\text { malformation } \\
(n=25)\end{array}$ & $4(16)$ & 0 & 1 & 2 & 0 & 0 & 0 & $\begin{array}{l}\text { Chromosome } \\
22 q(1)\end{array}$ & 0 \\
\hline Total $(n=240)$ & 43 (17.9) & 27 & 4 & 2 & 1 & 1 & 3 & 1 & 4 \\
\hline
\end{tabular}

Table 4 Rates of pCNV, likely pCNV and VOUS in the different types of CGIO

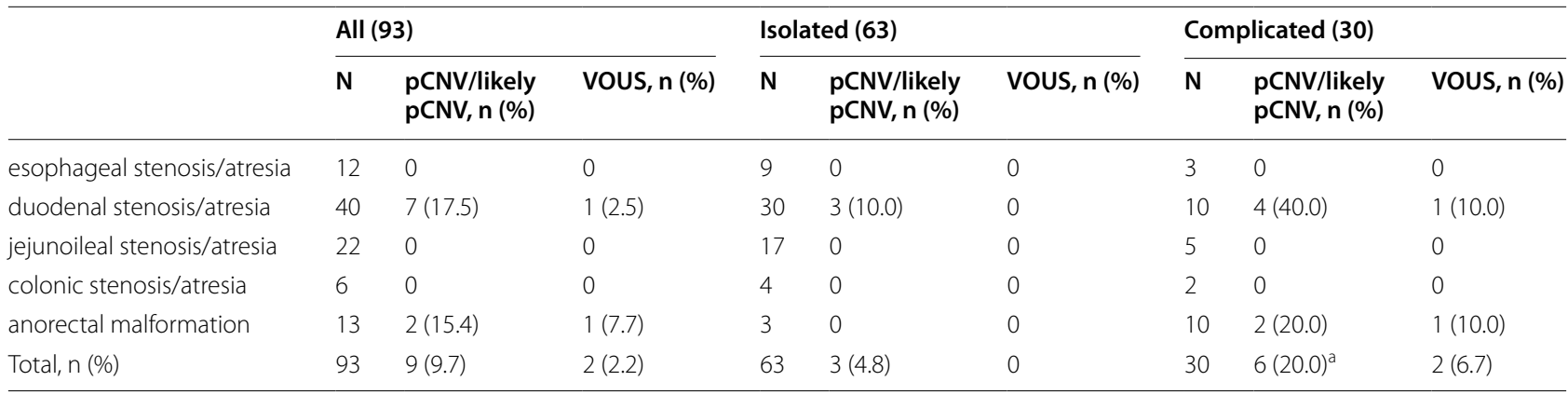

pCNV pathogenic copy number variants, VOUS variant of uncertain significance, CGIO congenital gastrointestinal atresia

${ }^{a}$ Differences between isolated CGIO and complicated CGIO groups were statistically significant $(P<0.05)$

cases with 22q11.2 duplication. Aberrations derived from $4 \mathrm{q}$ comprised one case of deletion and one case of duplication. Other associated chromosome anomalies in our study consisted of 10q26, 2p24 and 20p12.2.

In the isolated CGIO group, the overall detection rate of pCNVs or likely pCNVs was $4.8 \%$ (3/63). Considering only the isolated duodenal stenosis/atresia group, $\mathrm{pCNVs}$ and likely pCNVs were found in $10 \%$ of cases $(3 / 30)$. Meanwhile, the detection rate of pCNVs or likely pCNVs in fetuses with complicated CGIO was $20.0 \%(6 / 30)$, and the highest detection rate was in the duodenal stenosis/ atresia group, which was $40 \%$, followed by the anorectal malformation group $(20.0 \%, 2 / 10)$. The overall detection rate of pCNVs and likely pCNVs in the complicated CGIO group was significantly higher than that of the isolated CGIO group (20.0\% vs. $4.8 \%, p<0.05)$. Concerning subtypes of CGIO, abnormal CNVs were detected in the duodenal stenosis/atresia group $(17.5 \%, 7 / 40)$ and anorectal malformation group $(15.4 \%, 2 / 13)$, while no abnormal CNVs were detected in the esophageal stenosis/ atresia group, jejunoileum stenosis/atresia group or colonic intestine/stenosis group.

VOUS was reported in 2 cases of CGIO (2/93, 2.2\%), and both were in the complicated CGIO group. One duplication of uncertain significance was identified in duodenal stenosis/atresia in the absence of a nasal bone. One deletion of uncertain significance was identified in anorectal malformation with lymphangioma of the neck and a single umbilical artery.

\section{Follow-up}

Follow-up was obtained in $219(91.3 \%, 219 / 240)$ of our patients. Forty-three fetuses either died in utero or were terminated. Among the surviving infants, 9 cases were not found to have any gastrointestinal obstruction syndrome, and the postpartum imaging was normal; 8 cases were misdiagnosed, and the postpartum results were inconsistent with the prenatal diagnosis, including 4 cases of Hirschsprung's disease, 3 cases of intestinal volvulus, and 1 case of congenital choledochal cyst. 


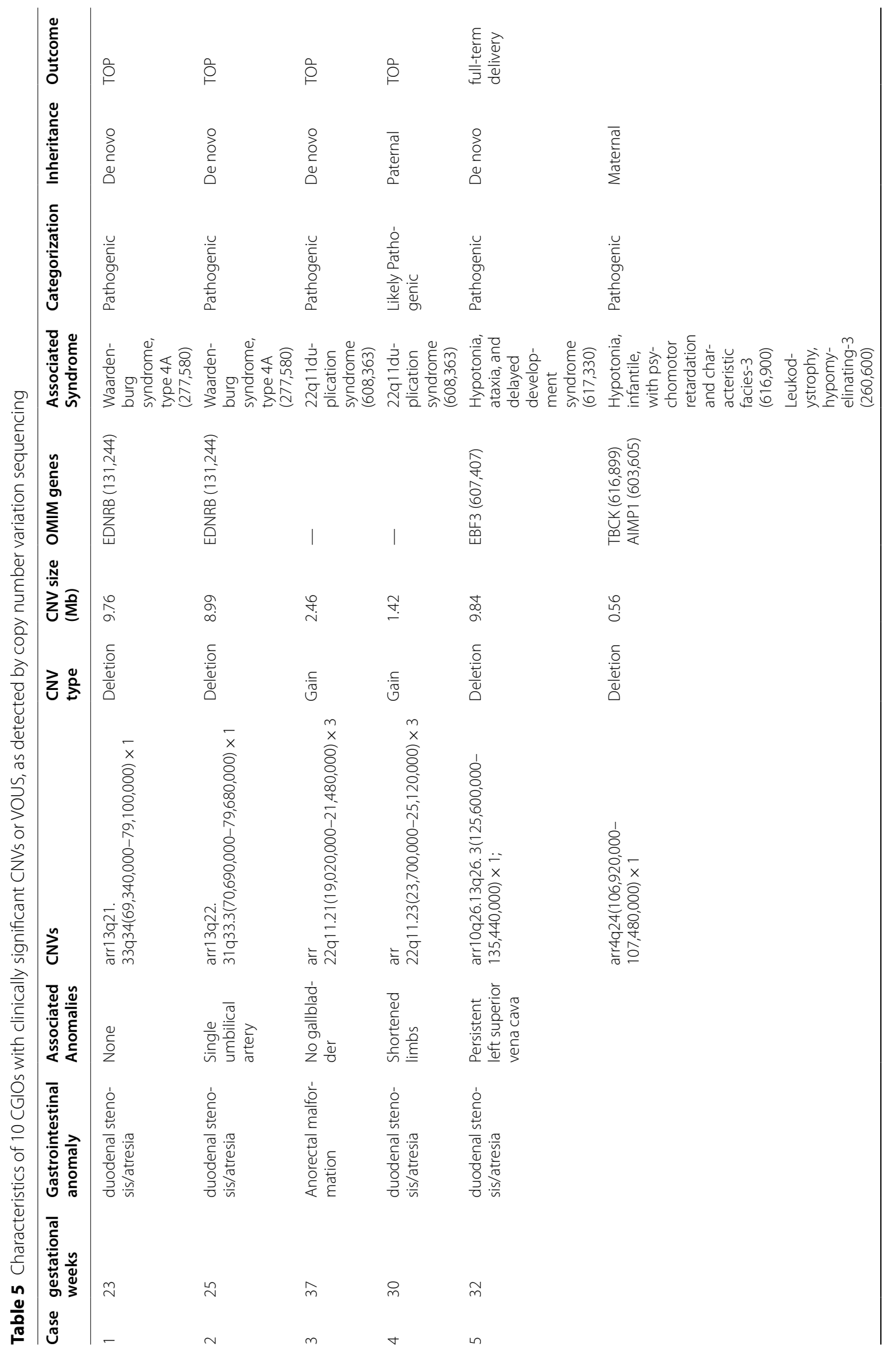




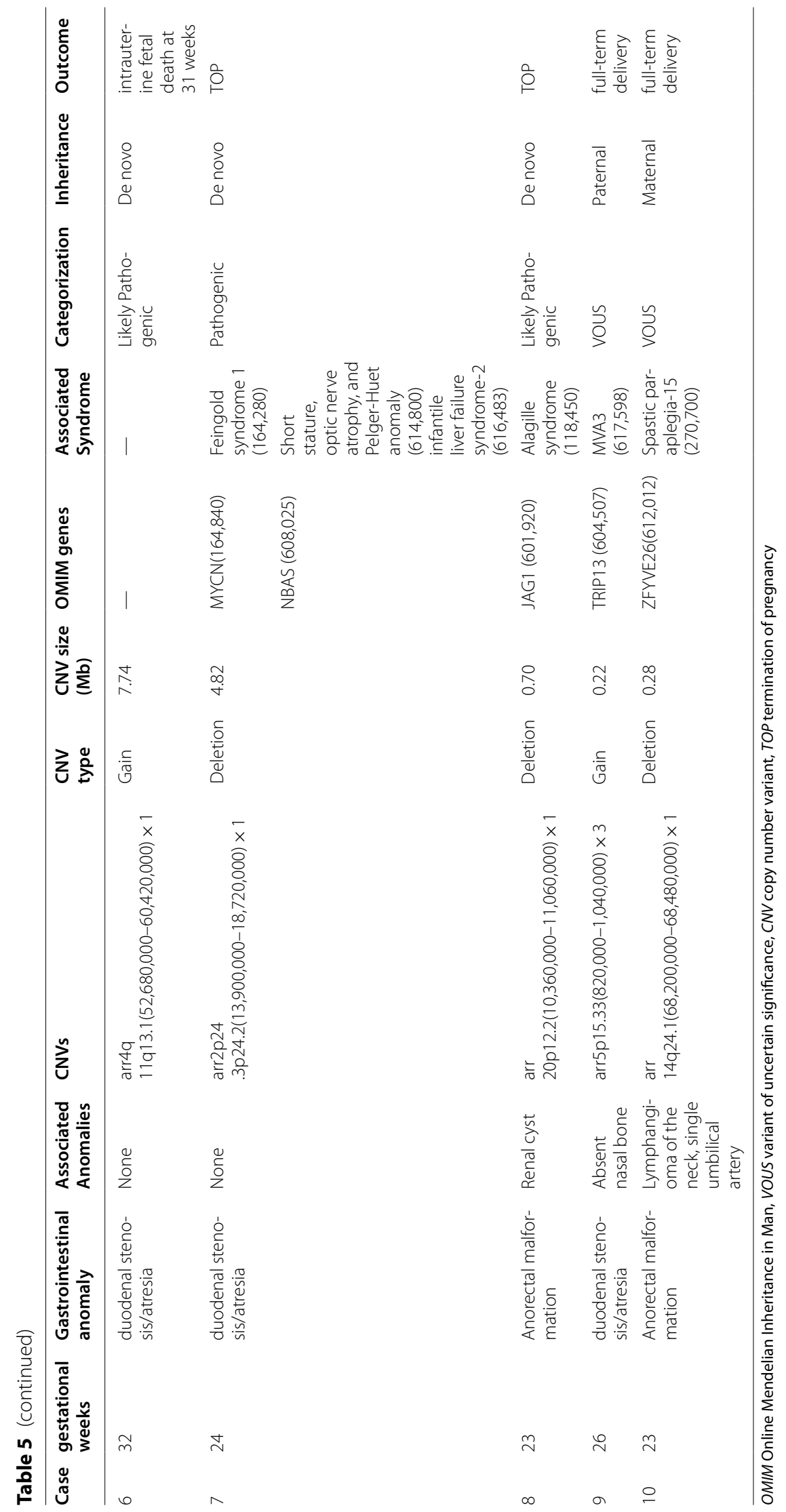


In addition, 3 infants had structural abnormalities that were not diagnosed by prenatal ultrasound, including 1 case of congenital hypoplasia of the penis, cryptorchid, and congenital cleft palate; 1 case of microtia; and 1 case of hypospadias and tethered cord syndrome. During the follow-up period, one infant with duodenal stenosis/atresia and persistent left superior vena cava with a 10q deletion (case 5) showed developmental delay, and the others showed no obvious phenotypic abnormality.

\section{Discussion}

Congenital gastrointestinal obstruction is one of the most frequent anomalies second to central nervous system anomalies in fetuses [17]. The causes of gastrointestinal atresia are complex, and chromosomal abnormalities constitute an important factor in its pathogenesis. Studies published to date have mainly focused on the relationship between aneuploid and CGIO. Up to $44 \%$ of fetuses with duodenal stenosis/atresia are associated with trisomy 21 [18-20] and may be higher if other chromosomal abnormalities are included. In our research, even if chromosome structure abnormalities were included, the rate of abnormal karyotypes (including trisomy 21) in cases with duodenal atresia was only $25 \%$, which was lower than that in previous studies. Becky et al. reported that only $15 \%(4 / 27)$ of cases with DA were diagnosed with trisomy 21, at a lower rate; the same was true in the study by Zhang et al., at a detection rate of $5.9 \%(3 / 51)$. Combined with our research, we believe that the association between duodenal atresia and trisomy 21 should be reconsidered because of the wide use of noninvasive prenatal testing (NIPT) and improvements in ultrasonographic techniques in the first trimester. In addition, we found that the prevalence of chromosomal anomalies in cases of isolated CGIO (10.8\%) was lower than that with complicated CGIO (33.8\%), consistent with that reported in previous studies [21], indicating that it is necessary to strengthen the observation of other structures or soft markers when CGIO is encountered.

Although both CMA and CNV-seq provide highresolution analysis for accurate and reliable diagnosis of clinically significant CNVs, CNV-seq does have some potential advantages over CMA, including high throughput sample analysis, lower gDNA input detection, and shorter turnaround time. In the past few years, several large studies published the incremental yield of CMA over karyotype in fetuses with ultrasonographic structure anomalies [22-24], but few studies were conducted on the relationship between $\mathrm{CNV}$-seq and karyotype. In 2018, a large prospective study that performed CNV-seq on 3429 amniotic fluid samples in fetuses with a low risk of $\mathrm{CNV}$ abnormalities showed that the incremental yield of $\mathrm{CNV}$-seq over karyotype was approximately $1 \%$ and first proposed that CNV-seq could be considered the first-tier diagnostic technique for detecting pCNVs [11]. Moreover, it was suggested that the frequency of pCNVs in fetuses with ultrasonographic abnormalities should be further refined by the organ system involved and the number of anomalies observed [25]. Xia et al. reported that the detection rates of pCNV and VOUS were $4.55 \%$ and $9.09 \%$ in digestive disorders, respectively [26]. In a recent study performed by Zhang et al. [15], pCNVs were identified in 5 of 48 fetuses with DO at a detection rate of $10.4 \%$. In our study, we observed different types of CGIO caused by stenosis or atresia. CNV-seq revealed an incremental diagnostic value of $9.7 \%$ over conventional karyotyping in fetuses with CGIO, and the genomic alterations differed between isolated CGIO and complicated CGIO. The incremental diagnostic yield of CNVseq in complicated CGIOs (20\%) was higher than that in isolated CGIOs (4.8\%), and the highest prevalence of pCNVs/likely pCNVs was found in the duodenal stenosis/atresia group (17.5\%), followed by the anorectal malformation group (15.4\%). These data were inconsistent with the reports by Bishop et al. [13] in which a pathogenic microdeletion was found only in isolated duodenal atresia and by Zhang et al. [15] in which no significant difference in pCNVs was observed between the isolated group and complicated group. However, we believe that the divergence might be due to the relatively low number of fetuses included in those studies.

The 13q deletion, resulting in Waardenburg syndrome type 4A (OMIM 277580), was the most frequently identified CNV in our study (cases 1 and 2). This finding was consistent with a finding in a previous study [15]. CNVseq revealed a 9.76-MB deletion in $13 \mathrm{q} 21.33 \mathrm{q} 34$ and an 8.99-MB deletion in 13q22.31q33.3. According to the AMC guidelines, they were both classified as pathogenic CNVs. The ClinGen database shows that the fragment contains the EDNRB gene, which is a signaling molecule and key component of the endothelin pathway and plays an important role in the migration of enteric nervous system (ENS) precursors within the gut [27]. Several studies reported that mutations of EDNRB were identified in Hirschsprung disease (HSCR, absence of enteric neurons in distal portions of the gut) and Waardenburg syndrome type 4A (WS4A, pigmentation defects and deafness due to altered development of melanocytes) [27-30]. Notably, abnormal migration of neural crest cells in conjunction with destruction of blood vessels may be the possible pathogenesis of duodenal atresia. Meanwhile, the relationship between 13q deletion and duodenal atresia has been described in several case reports [15, 31, 32]. In summary, we consider that haploinsufficiency of EDNRB might be a candidate gene to produce the phenotype of 
duodenal stenosis/atresia in a fetus with $13 q$ deletion syndrome.

Another variant that occurred with high frequency was 22q11.2 microduplication, which was present in one case of anorectal malformation (case 3 ) and one case of duodenal atresia (case 4). The 22q11.2 duplication is associated with mild but highly variable phenotypes, ranging from normal to developmental delay, growth restriction, hypotonia, and intellectual disability [33]. Due to incomplete penetrance and variable phenotypes, this $\mathrm{CNV}$ can cause parental anxiety about the future health and development of their children. Although the effects of these potentially pathogenic abnormalities do not appear after birth or for a long time after birth, the limited information on 22q11.2 duplication is not trivial. Providing parents with this information may not only help parents better understand abnormalities that may occur in their children but also help families take better care of them and seek therapeutic intervention earlier.

Case 5 was a fetus with a 9.84-Mb 10q26.13q26.3 deletion (de novo) and a $0.56-\mathrm{Mb} 4 \mathrm{q} 24$ deletion (maternal) with duodenal atresia and persistent left superior vena cava on prenatal ultrasound. The deletion of 10q26 includes the EBF3 gene, of which low expression has been linked to hypotonia, ataxia, and delayed development syndrome (OMIM 617330), resulting in various congenital abnormalities, including microcephaly, growth retardation, intellectual disability, craniofacial dysmorphism, micropenis, cryptorchidism, etc. [34-37]. Maruyama et al. reported a patient with duodenal atresia combined with partial monosomy $10 \mathrm{q}$ with partial trisomy 11q, showing that the synergistic effects of partial monosomy 10q and partial trisomy 11q on the phenotype might be related to the development of duodenal atresia [38]. The deletion of 4q24 encompasses the TBCK and AIMP1 genes, and loss of them may be responsible for psychomotor retardation. Bishop et al. [13] reported a case of isolated duodenal atresia who had a likely pathogenic microdeletion of chromosome 4q22.3. Therefore, the literature, combined with our current results, suggests that 10q26 and 4q24 microdeletions might be additional genetic etiologies of duodenal stenosis/atresia.

Case 7, a fetus with duodenal atresia, had a $4.82-\mathrm{Mb}$ deletion in chromosome 2p24.3p24.2. This segment contains the genes MYCN and NBAS. MYCN is significantly associated with Feingold syndrome-1 (FGLDS1), which is characterized by esophageal and duodenal atresia, microcephaly, limb malformation, and mental retardation. Vertebral anomalies, cardiac malformations, and deafness have also been reported in a minority of patients [39]. NBAS is associated with infantile liver failure syndrome, short stature and optic nerve atrophy [40, 41]. Although diagnosed with a normal karyotype, TOP was chosen for this patient due to pathogenic CNV. For the deletion of $20 \mathrm{p} 12.2$ and the duplication of $4 \mathrm{q}$ in our reports, there are no previous studies about their association with congenital gastrointestinal deformities and were considered to be incidental findings by us. In addition, two VOUS were detected in one case with duodenal atresia and one case with anorectal malformation accompanied by other structural abnormalities. The fetuses were both delivered at term, showing no obvious phenotypic abnormality up to the time the article was written.

The mortality rate of CGIO is usually low. Most neonates with these conditions can be relieved by surgery, and the overall outcome is good; however, the premise is that there are no genetic abnormalities in prenatal diagnosis. Submicroscopic chromosome aberrations should be considered in addition to aneuploidies. In our study, no pathogenic CNVs were found in esophageal stenosis/ atresia, jejunoileum stenosis/atresia or colonic intestine/ stenosis. Rare inherited and de novo CNVs were identified in fetuses with esophageal atresia. A multicenter study detected 375 patients with esophageal atresia and found that $2.7 \%$ had pathogenic CNVs, expanding the genetic scope of esophageal atresia [42]. Therefore, the correlation between esophageal atresia and CNVs still requires a large number of case studies and targeted genotype-phenotype analysis. Approximately 55\% of infants born with esophageal atresia have other anomalies or birth defects, $10 \%$ of infants have a nonrandom VACTERL syndrome, and $1 \%$ of infants also have CHARGE syndrome, so fetuses with esophageal atresia require detailed imaging and genetic testing to assess the risk [43-46]. Research has suggested that the occurrence of jejunoileum stenosis/atresia is related to race and maternal age, and the correlation between them and chromosomal abnormalities is lower than that of duodenal atresia and esophageal atresia [47]. In 2015, a number of European research centers retrospectively analyzed 423 cases of jejunoileum stenosis/atresia and found that the prevalence of chromosomal abnormalities was 3.8\% and that of aneuploidy was only $0.3 \%$ [21]. These findings demonstrated that the incidence of chromosomal abnormalities of jejunoileum stenosis/atresia was relatively low. The mechanism of colonic atresia is generally accepted to be vascular injury. This may be the reason for its low incidence of chromosomal abnormalities. Meanwhile, the weak connection between chromosomal abnormalities and jejunoileum stenosis/atresia and colonic intestine/ stenosis observed in our study provides information for clinical prenatal counseling and decision-making.

There are several limitations in our study. First, as a retrospective study, there were limited numbers of some categories of CGIO, and less than half of the fetuses underwent $\mathrm{CNV}$-seq. Therefore, the $\mathrm{pCNV}$ and 
likely pCNV rates of different subgroups may change if the sample size was expanded. Second, not all fetal CGIOs were confirmed, and some misdiagnosed cases were included in our study. We should accept that these factors might influence the rates of chromosomal abnormalities to a certain extent. Finally, not all women with CGIO underwent amniocentesis or cordocentesis, which might be relevant from the perspective of selection bias. Some results found in our study also differed from previous reports. The abnormal genetic results found in our study may not represent the majority of CGIO abnormalities but can also expand the genetic scope of CGIO to some extent. In the future, more cases need to be collected, likely in cooperation with multiple centers, to conduct further statistical analysis and to generate a more complete summary of the findings.

\section{Conclusion}

In summary, our study showed that the risk of pathogenic chromosomal abnormalities and CNVs was increased in the complicated CGIO group compared to that in the isolated CGIO group, especially with DO and anorectal malformation. CNC-seq was recommended to detect submicroscopic chromosomal aberrations for DO and anorectal malformation with a normal karyotype, as the information derived can provide additional clinically relevant information. The relationship between genotypes and phenotypes needs to be explored in the future to facilitate prenatal diagnosis of fetal CGIO and provide new clues into their etiologies.

\section{Abbreviations}

CGIO: Congenital gastrointestinal obstruction; NGS: Next-generation sequencing; CNV-seq: Copy number variation sequencing; DO: Duodenal obstruction; SD: Standard deviation; BMI: Body mass index; TOP: Termination of pregnancy; pCNV: Pathogenic copy number variants; VOUS: Variant of uncertain significance; OMIM: Online Mendelian Inheritance in Man; CNV: Copy number variant.

\section{Acknowledgements \\ Not applicable.}

\section{Authors' contributions}

XM: Study design, data acquisition, data analysis, manuscript writing. LJ: project development, data management, data analysis, manuscript editing. All authors read and approved the final version of the manuscript.

\section{Funding}

Not applicable.

\section{Availability of data and materials}

The datasets generated and/or analyzed during the current study are not publicly available due to the pregnancies who participated in the study did not agree to use their individual data for publicity in the research, but are available from the corresponding author on reasonable request.

\section{Declarations}

Ethics approval and consent to participate

All procedures performed in this study were in accordance with the ethical standards of the Hospital Human Subjects Ethics Committee, Shengjing Hospital of China Medical University. This study was approved by the Hospital Human Subjects Ethics Committee and any consent to participate was obtained from those who were contacted via telephone. Consent obtained from all participants was verbal and the ethics committee approved this procedure.

\section{Consent for publication}

Not applicable.

\section{Competing interests}

The authors declare that they have no competing interests.

\section{Author details}

${ }^{1}$ Department of Ultrasound, Shengjing Hospital of China Medical University, Shenyang, China. ${ }^{2}$ Department of Obstetrics and Gynecology, Shengjing Hospital of China Medical University, NO. 36, Sanhao Street, Liaoning Province 110004 Shenyang, China.

Received: 19 August 2021 Accepted: 12 January 2022

Published online: 19 January 2022

References

1. Celli J. Genetics of gastrointestinal atresias. Eur J Med Genet. 2014;57(8):424-39.

2. Hemming V, Rankin J. Small intestinal atresia in a defined population: occurrence, prenatal diagnosis and survival. Prenat Diagn. 2007;27(13):1205-11.

3. Wang $X$, Yuan $C$, Xiang $L$, Li X, Zhao Z, Jin X. The clinical significance of pathological studies of congenital intestinal atresia. J Pediatr Surg. 2013:48(10):2084-91.

4. Gupta A, Bischoff A, Peña A, Runck LA, Guasch G. The great divide: septation and malformation of the cloaca, and its implications for surgeons. Pediatr Surg Int. 2014;30(11):1089-95.

5. Nichol PF, Reeder A, Botham R. Humans, mice, and mechanisms of intestinal atresias: a window into understanding early intestinal development. J Gastrointest Surg. 2011;15(4):694-700.

6. van Lennep M, Singendonk MMJ, Dall'Oglio L, Gottrand F, Krishnan U, Terheggen-Lagro SWJ, et al. Oesophageal atresia Nat Rev Dis Primers. 2019;5(1):26

7. Jones MLM, Sarila G, Chapuis P, Hutson JM, King SK, Teague WJ. The Role of Fibroblast Growth Factor 10 Signaling in Duodenal Atresia. Front Pharmacol. 2020;11:250.

8. Khan A, Tanny ST, Perkins EJ, Hunt RW, Hutson JM, King SK, et al. Is selective echocardiography in duodenal atresia the future standard of care? J Pediatr Surg. 2017;52(12):1952-5.

9. Lupo PJ, Isenburg JL, Salemi JL, Mai CT, Liberman RF, Canfield MA, et al. Population-based birth defects data in the United States, 2010-2014: A focus on gastrointestinal defects. Birth Defects Res. 2017;109(18):1504-14.

10. Hardwick SA, Deveson IW, Mercer TR. Reference standards for next-generation sequencing. Nat Rev Genet. 2017;18(8):473-84.

11. Wang J, Chen L, Zhou C, Wang L, Xie H, Xiao Y, et al. Prospective chromosome analysis of 3429 amniocentesis samples in China using copy number variation sequencing. Am J Obstet Gynecol. 2018;219(3):287-e1.

12. Wang H, Dong Z, Zhang R, Chau MHK, Yang Z, Tsang KYC, et al. Low-pass genome sequencing versus chromosomal microarray analysis: implementation in prenatal diagnosis. Genet Med. 2020;22(3):500-10.

13. Bishop JC, McCormick B, Johnson CT, Miller J, Jelin E, Blakemore K, et al. The Double Bubble Sign: Duodenal Atresia and Associated Genetic Etiologies. Fetal Diagn Ther. 2020;47(2):98-103.

14. Quintero-Rivera F, Woo JS, Bomberg EM, Wallace WD, Peredo J, Dipple KM. Duodenal atresia in 17q12 microdeletion including HNF1B: a new associated malformation in this syndrome. Am J Med Genet A. 2014;164(12):3076-82. 
15. Zhang W, Lei T, Fu F, Deng Q, Li R, Wang D, et al. Microarray analysis in fetuses with duodenal obstruction: It is not just trisomy 21. Prenat Diagn. 2021;41(3):316-22.

16. Kearney HM, Thorland EC, Brown KK, Quintero-Rivera F, South ST. American College of Medical Genetics standards and guidelines for interpretation and reporting of postnatal constitutional copy number variants. Genet Med. 2011;13(7):680-5.

17. Gourevitch A. Duodenal atresia in the newborn. Ann R Coll Surg Engl. 1971;48(3):141-58.

18. Buchin PJ, Levy JS, Schullinger JN. Down's syndrome and the gastrointestinal tract. J Clin Gastroenterol. 1986;8(2):111-4

19. Choudhry MS, Rahman N, Boyd P, Lakhoo K. Duodenal atresia: associated anomalies, prenatal diagnosis and outcome. Pediatr Surg Int. 2009;25(8):727-30.

20. Keckler SJ, St Peter SD, Spilde TL, Ostlie DJ, Snyder CL. The influence of trisomy 21 on the incidence and severity of congenital heart defects in patients with duodenal atresia. Pediatr Surg Int. 2008;24(8):921-3.

21. Haeusler MC, Berghold A, Stoll C, Barisic I, Clementi M. Prenatal ultrasonographic detection of gastrointestinal obstruction: results from 18 European congenital anomaly registries. Prenat Diagn. 2002;22(7):616-23.

22. Srebniak MI, Diderich KE, Joosten M, Govaerts LC, Knijnenburg J, de Vries FA, et al. Prenatal SNP array testing in 1000 fetuses with ultrasound anomalies: causative, unexpected and susceptibility CNVs. Eur J Hum Genet. 2016;24(5):645-51.

23. Hillman SC, McMullan DJ, Hall G, Togneri FS, James N, Maher EJ, et al. Use of prenatal chromosomal microarray: prospective cohort study and systematic review and meta-analysis. Ultrasound Obstet Gynecol. 2013;41(6):610-20.

24. Shaffer LG, Dabell MP, Fisher AJ, Coppinger J, Bandholz AM, Ellison JW et al. Experience with microarray-based comparative genomic hybridization for prenatal diagnosis in over 5000 pregnancies. Prenat Diagn. 2012;32(10):976-85.

25. Levy B, Wapner R. Prenatal diagnosis by chromosomal microarray analysis. Fertil Steril. 2018;109(2):201-12.

26. Xia M, Yang X, Fu J, Teng Z, Lv Y, Yu L. Application of chromosome microarray analysis in prenatal diagnosis. BMC Pregnancy Childbirth. 2020;20(1):696.

27. Bondurand N, Dufour S, Pingault V. News from the endothelin-3/EDNRB signaling pathway: Role during enteric nervous system development and involvement in neural crest-associated disorders. Dev Biol. 2018;444(Suppl 1):S156-69.

28. Issa S, Bondurand N, Faubert E, Poisson S, Lecerf L, Nitschke P, et al. EDNRB mutations cause Waardenburg syndrome type II in the heterozygous state. Hum Mutat. 2017;38(5):581-93.

29. Pingault V, Ente D, Dastot-Le Moal F, Goossens M, Marlin S, Bondurand N. Review and update of mutations causing Waardenburg syndrome. Hum Mutat. 2010;31(4):391-406.

30. de Lumley WL, Boulesteix J, Rutkowski J, Umdenstock R. Waardenburg syndrome associated with Hirschsprung disease and other abnormalities. Pediatrics. 1980;65(2):368-9.

31. Khong TY, Ford WD, Haan EA. Umbilical cord ulceration in association with intestinal atresia in a child with deletion 13q and Hirschsprung's disease. Arch Dis Child Fetal Neonatal Ed. 1994;71(3):F212-3.

32. Miyake H, Yamamoto A, Yamada T, Okazaki K, Morita K, Kondo M, et al. Umbilical cord ulceration after prenatal diagnosis of duodenal atresia with interstitial deletion of chromosome 13q: a case report. Fetal Diagn Ther. 2008:24(2):115-8.

33. Goldenberg P. An Update on Common Chromosome Microdeletion and Microduplication Syndromes. Pediatr Ann. 2018;47(5):e198-203.

34. Vera-Carbonell A, López-González V, Bafalliu JA, Ballesta-Martínez MJ, Fernández A, Guillén-Navarro E, et al. Clinical comparison of 10q26 overlapping deletions: delineating the critical region for urogenital anomalies. Am J Med Genet A. 2015;167(4):786-90.

35. Ramos M, Wilkens A, Krantz ID, Wu Y. Hearing loss, coloboma and left ventricular enlargement in a boy with an interstitial 10q26 deletion. Am J Med Genet C Semin Med Genet. 2016;172(2):109-16.

36. Yatsenko SA, Kruer MC, Bader PI, Corzo D, Schuette J, Keegan CE, et al. Identification of critical regions for clinical features of distal $10 \mathrm{q}$ deletion syndrome. Clin Genet. 2009;76(1):54-62.

37. Sutani A, Shima H, Hijikata A, Hosokawa S, Katoh-Fukui Y, Takasawa K, et al. WDR11 is another causative gene for coloboma, cardiac anomaly and growth retardation in 10q26 deletion syndrome. Eur J Med Genet. 2020;63(1):103626.

38. Maruyama K, Koizumi T, Ikeda H. Partial monosomy 10q with partial trisomy $11 \mathrm{q}$ due to paternal balanced translocation. J Paediatr Child Health. 2001;37(2):198-200.

39. Tészás A, Meijer R, Scheffer H, Gyuris P, Kosztolányi G, van Bokhoven H, et al. Expanding the clinical spectrum of MYCN-related Feingold syndrome. Am J Med Genet A. 2006;140(20):2254-6.

40. Maksimova N, Hara K, Nikolaeva I, Chun-Feng T, Usui T, Takagi M, et al. Neuroblastoma amplified sequence gene is associated with a novel short stature syndrome characterised by optic nerve atrophy and Pelger-Huët anomaly. J Med Genet. 2010;47(8):538-48.

41. Haack TB, Staufner C, Köpke MG, Straub BK, Kölker S, Thiel C, et al. Biallelic Mutations in NBAS Cause Recurrent Acute Liver Failure with Onset in Infancy. Am J Hum Genet. 2015;97(1):163-9.

42. Brosens E, Marsch F, de Jong EM, Zaveri HP, Hilger AC, Choinitzki VG, et al. Copy number variations in 375 patients with oesophageal atresia and/or tracheoesophageal fistula. Eur J Hum Genet. 2016;24(12):1715-23.

43. Pedersen RN, Calzolari E, Husby S, Garne E. Oesophageal atresia: prevalence, prenatal diagnosis and associated anomalies in 23 European regions. Arch Dis Child. 2012;97(3):227-32.

44. Stoll C, Alembik Y, Dott B, Roth MP. Associated anomalies in cases with esophageal atresia. Am J Med Genet A. 2017;173(8):2139-57.

45. Solomon BD, Bear KA, Kimonis V, de Klein A, Scott DA, Shaw-Smith C, et al. Clinical geneticists' views of VACTERLNATER association. Am J Med Genet A. 2012;158(12):3087-100

46. Wyse RK, al-Mahdawi S, Burn J, Blake K. Congenital heart disease in CHARGE association. Pediatr Cardiol. 1993;14(2):75-81.

47. Forrester MB, Merz RD. Population-based study of small intestinal atresia and stenosis, Hawaii, 1986-2000. Public Health. 2004;118(6):434-8.

\section{Publisher's Note}

Springer Nature remains neutral with regard to jurisdictional claims in published maps and institutional affiliations.

Ready to submit your research? Choose BMC and benefit from

- fast, convenient online submission

- thorough peer review by experienced researchers in your field

- rapid publication on acceptance

- support for research data, including large and complex data types

- gold Open Access which fosters wider collaboration and increased citations

- maximum visibility for your research: over $100 \mathrm{M}$ website views per year

At BMC, research is always in progress.

Learn more biomedcentral.com/submissions 